\title{
Results of treatment of anisohypermetropic amblyopia without strabismus
}

\author{
DHAN KRISHNA SEN
}

From the Department of Ophthalmology, Maulana Azad Medical College and Lok Nayak Jai Prakash Narayan Hospital, and Guru Nanak Eye Centre, New Delhi, India

SUMMARY One hundred and two patients with anisohypermetropic amblyopia without strabismus were studied. Microstrabismus was excluded by detailed orthoptic examinations including visuscopy and Cüppers' bifoveal correspondence test. Treatment consisted in wearing correcting glasses and part-time or full-time patching of the nonamblyopic eye. In patients with dense amblyopia patching of the amblyopic eye was done and Cüppers' after-image method of pleoptic therapy was instituted as the initial procedure. When visual acuity improved sufficiently by this therapy, patching was used on the nonamblyopic eye. Sixty-five $(63.7 \%)$ patients showed 2 lines or more improvement on the Snellen chart. Though young children (6 to 12 years) improved their visual acuity more often than those aged 13 to 20 years, a considerable number of patients $(50.0 \%)$ in the older age group improved their visual acuity after therapy. The improvement in visual acuity was accompanied by improved stereoacuity in $49.0 \%$ of the patients. It is therefore suggested that every effort should be made to treat these patients even after the age of 12 years.

It is becoming increasingly common for strabismic amblyopia to be detected and treated at an early age. However, anisometropic amblyopia without strabismus usually remains undetected until the child's eyes are examined at the school health clinic. Since in this country health clinics in many schools are nonexistent or are poorly organised, many children with anisometropic amblyopia remain undetected even in the early years of their school life. Consequently many of them report to us at a more advanced age.

Most cases of anisometropic amblyopia are believed to have a good prognosis if treatment is instituted early, ${ }^{1-3}$ and it has generally been held that treatment of anisometropic children over the age of 12 gives poor results. ${ }^{45}$ In our clinic, however, we have been able to obtain good results in many children even over the age of 12 years.

The main purpose of this paper is to review the results obtained by treating patients in the age groups 6 to 12 years and 13 to 20 years and to analyse the data statistically to see if there is any difference in the results in the 2 age groups.

Correspondence to Dr D. K. Sen, V/4 MAM College Campus, Kotla Road, New Delhi 110002 , India.

\section{Patients and methods}

There are 2 categories of patients with unilateral visual impairment in straight eyes, namely, those with (a) anisometropic amblyopia with central fixation, normal correspondence, and bifoveolar fixation, and (b) amblyopia in microstrabismus (microtropia).

Since anisometropia is a consistent finding in almost all cases in the above 2 groups, it is very important to differentiate them before any treatment is undertaken, as the prognosis for improvement of vision in microstrabismus is extremely poor. ${ }^{1}$ In our cases microstrabismus was excluded by orthoptic examinations, including visuscopy to demonstrate parafoveal eccentric fixation and Cüppers' bifoveal correspondence test to show anomalous retinal correspondence. Bifoveal fixation was also tested by having the patient superimpose Haidinger's brushes on a real object.

A refraction under full cycloplegia was done in all cases at the beginning, and 102 patients with anisohypermetropia whose vision did not become equal to that of the less ametropic eye even after full-time wearing of glasses for 6 weeks or more were selected for treatment. Their eyes were otherwise normal, 
with central fixation, normal correspondence, and bifoveolar fixation. Their ages ranged from 6 to 20 years. Fifty-six patients were between 6 and 12 years and 46 patients were between 13 and 20 years.

In patients with visual acuity $6 / 12$ or $6 / 18$ in the amblyopic eye part-time patching of the nonamblyopic eye was undertaken. They were encouraged to do exercises involving hand-eye coordination like reading, colouring, tracing, looking for and pointing out details in pictures, drawing, doing jigsaw puzzles, and so on, while the nonamblyopic eye was covered by the patch to provide enough stimulation to the fovea of the amblyopic eye. When the visual acuity did not become equal to that of the better eye under this regimen, full-time patching of the nonamblyopic eye was carried out. In patients with visual acuity $6 / 24$ or $6 / 36$ full-time patching of the nonamblyopic eye was done from the beginning. The patients were evaluated for progress once a week.

Improvement in visual acuity was determined in each patient by recording the differences in lines of visual acuity (Snellen) before and after treatment. As the significance of an improvement of one line on the Snellen chart is questionable, only the patients in whom there were at least 2 lines of improvement at the end of treatment were listed as having 'improved.' Patching of the nonamblyopic eye was continued as long as improvement in visual acuity was seen. The period of patching ranged from 2 to 18 months. When vision had sufficiently improved, the patients were asked to do exercises involving hand-eye coordination. The cases were regarded as failures when there was no improvement or only one line improvement after full-time patching of the better eye for a period of 4 months.

In patients with severe amblyopia, visual acuity $6 / 60$ or worse, patching of the amblyopic eye was done and Cüppers' after-image method of pleoptic therapy was instituted as the initial procedure. The pupil of the amblyopic eye was fully dilated. The nonamblyopic eye was kept firmly closed. Then the after-image was produced in the amblyopic eye with a projectoscope fitted with a Nutt autodisc ${ }^{6}$ after protecting the central area with a black round disc. The formation and observation of the after-image was facilitated by means of a flashing illumination on a white wall in the testing room, the dark and the light periods of the flashing being regulated independently. When the patient appreciated the negative afterimage, he was asked to superimpose it upon real images in various positions on the wall at a distance of about 1 metre. Hand-eye co-ordination was encouraged by having the patient touch the centre of the after-image, first with his finger and later, when the exercises were carried out at a greater distance from the wall, with a pointer. The fixation objectthe finger or the pointer-and the centre of the afterimage had to be superimposed. The fixation object used at first was large and of simple form like + . As vision improved the fixation object was replaced by letters of decreasing sizes, and the exercises were carried out at increasing distances from the wall.

The procedure was repeated several times during each treatment session. Patients were treated daily for 5 days a week, each treatment session lasting $\mathbf{3 0}$ minutes. When visual acuity had improved sufficiently by this therapy, patching was used on the nonamblyopic eye, and the patients were encouraged to do exercises like reading, tracing, etc. A minimum of 60 pleoptic sessions were given before a case was declared hopeless and the therapy abandoned.

Once the best possible visual acuity in the amblyopic eye was obtained, the period of patching of the nonamblyopic eye was gradually reduced, depending on the individual requirement to maintain the optimum level of visual acuity in the amblyopic eye. In all cases when the vision became normal, or near normal, orthoptic exercises were given to improve binocular functions. Finally all the patients were directed to continue patching of the nonamblyopic eye once a week for about 3 hours as a precautionary measure to maintain the gain in vision. Since the patching was done on Sundays, and the time of day during which the patch was worn (watching television at home, doing homework for school, and so on) was such that it did not interfere with their social and outdoor activities, they had no difficulty in following our advice. The visual acuity and refraction were rechecked at 6-month intervals. The patients were followed up for a period of 3 to 4 years.

\section{Results}

Overall improvement in visual acuity after treatment was seen in $65(63.7 \%)$ of the patients. To compare the results obtained in the 2 age groups the patients were divided into 2 subgroups based on corrected initial visual acuity: $(a)$ patients with corrected initial visual acuity $6 / 24$ or better, (b) patients with corrected initial visual acuity $6 / 36$ or worse. The results were also analysed in relation to the degree of astigmatism in the amblyopic eyes and to the degree of anisometropia.

The amblyopic eye was astigmatic in $95(93.1 \%)$ of the 102 patients; the astigmatism ranged between 0.5 and 5.0 dioptres; in $20(19.6 \%)$ patients the astigmatism was 3 dioptres or more. The mean astigmatism in the group of patients (65) whose vision improved with treatment was 1.8 dioptres (range 0 to 5 dioptres) and in the group of patients (37) whose vision did not improve with treatment was $1 \cdot 5$ dioptres 


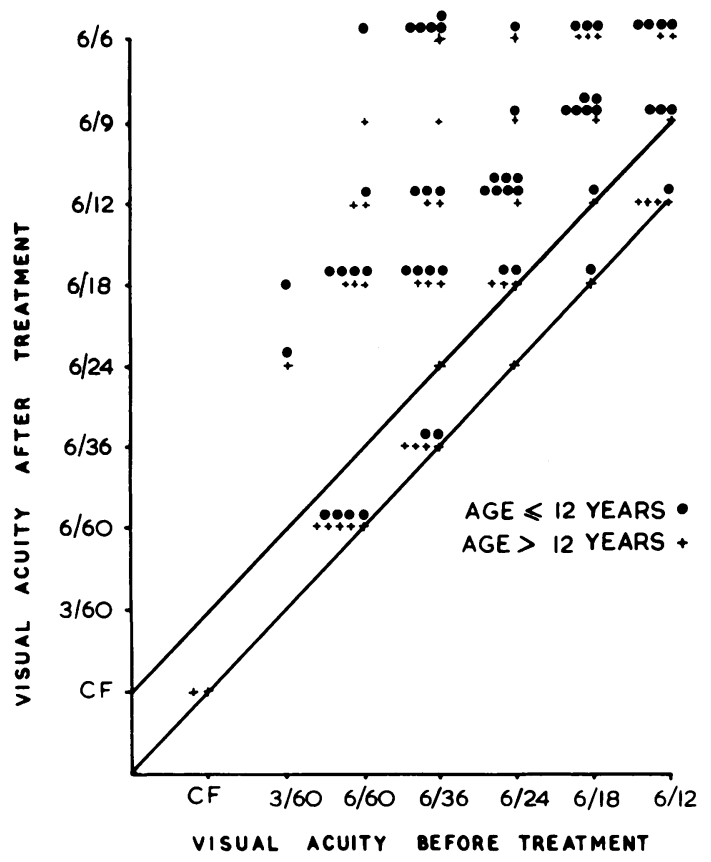

Fig. 1 Improvement in visual acuity after treatment as related to age in cases of anisohypermetropic amblyopia.

(range 0 to 4 dioptres). The difference in the mean astigmatism between the 2 groups is not statistically significant $\left(\chi^{2}=3.04\right.$ for $\left.3 \mathrm{DF}, \mathrm{p}>0 \cdot 30\right)$. In the former group of patients high astigmatism of 3.0 dioptres or more was present in $23.1 \%$ as against $13.5 \%$ in the latter group. This difference is also not statistically significant $\left(\chi^{2}=1 \cdot 37\right.$ for $\left.1 \mathrm{DF}, \mathrm{p}>0 \cdot 20\right)$. These figures indicate that astigmatism in the amblyopic eye did not play any role in the outcome of treatment in this series. The spherical equivalent of the cylindrical component was added to the sphere to find out the difference in the refractive error between the 2 eyes, which ranged between 1.5 and 9.0 dioptres (mean 4.43 dioptres). In the analysis of the results the cases were also subdivided into (a) patients with

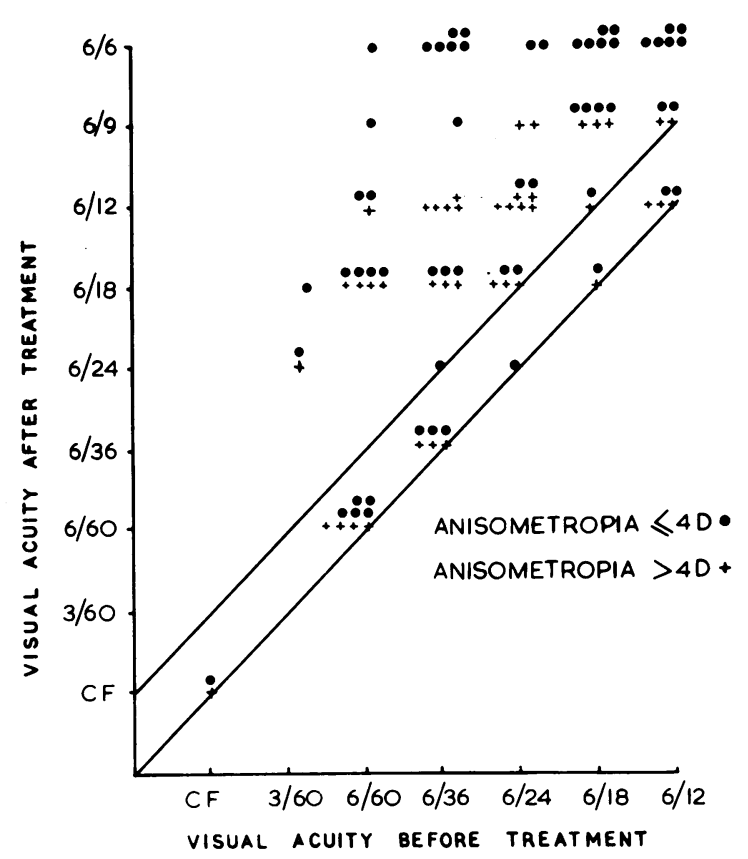

Fig. 2 Improvement in visual acuity after treatment as related to degree of anisometropia in cases of anisohypermetropic amblyopia.

anisometropia 4 dioptres or less (59 patients), and (b) patients with anisometropia greater than 4 dioptres (43 patients).

Figs. 1 and 2 chart the visual acuity before treatment against visual acuity after treatment as related to age and degree of anisometropia respectively. The patients appearing on the diagonal line did not show any improvement at all. Another line drawn parallel to the diagonal line indicates patients in whom only one line improvement was registered. As stated earlier these patients were also regarded as 'not improved.' Thus, only the patients appearing above the latter line were regarded as 'improved.' Table 1 gives the lines of improvement related to the age of the patients and Table 2 gives the

Table 1 Visual improvement in relation to age and corrected initial visual acuity

\begin{tabular}{|c|c|c|c|c|c|}
\hline \multirow{2}{*}{$\begin{array}{l}\text { Improvement in vision } \\
\text { on Snellen chart }\end{array}$} & \multicolumn{2}{|c|}{ Corrected initial visual acuity $6 / 24$ or better } & \multicolumn{2}{|c|}{ Corrected initial visual acuity $6 / 36$ or worse } & \multirow{2}{*}{$\begin{array}{l}\text { Total number } \\
\text { of cases }\end{array}$} \\
\hline & 6 to $12 \mathrm{Yr}$ & 13 to $20 \mathrm{Yr}$ & $6 t o 12 \mathrm{Yr}$ & 13 to $20 \mathrm{Yr}$ & \\
\hline $0-1$ line & $8(26 \cdot 7 \%)$ & $11(55 \cdot 0 \%)$ & $6(23 \cdot 1 \%)$ & $12(46 \cdot 2 \%)$ & $37(36 \cdot 3 \%)$ \\
\hline 2 lines & $16(53.3 \%)$ & $4(20.0 \%)$ & $3(11.5 \%)$ & $3(11 \cdot 5 \%)$ & $26(25 \cdot 5 \%)$ \\
\hline 3 lines & $5(16.7 \%)$ & $4(20.0 \%)$ & $9(34.6 \%)$ & $6(23 \cdot 1 \%)$ & $24(23.5 \%)$ \\
\hline 4 lines & $1(3 \cdot 3 \%)$ & $1(5 \cdot 0 \%)$ & $2(7 \cdot 7 \%)$ & $3(11.5 \%)$ & $7(6.9 \%)$ \\
\hline 5 lines & - & - & $6(23 \cdot 1 \%)$ & $2(7 \cdot 7 \%)$ & $8(7 \cdot 8 \%)$ \\
\hline Total number of cases & $30(100 \cdot 0 \%)$ & $20(100 \cdot 0 \%)$ & $26(100 \cdot 0 \%)$ & $26(100 \cdot 0 \%)$ & $102(100 \cdot 0 \%)$ \\
\hline
\end{tabular}


Table 2 Visual improvement in relation to degree of anisometropia and corrected initial visual acuity

\begin{tabular}{|c|c|c|c|c|c|}
\hline \multirow{2}{*}{$\begin{array}{l}\text { Improvement in vision } \\
\text { on Snellen chart }\end{array}$} & \multicolumn{2}{|c|}{ Corrected initial visual acuity $6 / 24$ or better } & \multicolumn{2}{|c|}{ Corrected initial visual acuity $6 / 36$ or worse } & \multirow{2}{*}{$\begin{array}{l}\text { Total number } \\
\text { of cases }\end{array}$} \\
\hline & $4 D$ or less & More than $4 D$ & $4 D$ orless & More than $4 D$ & \\
\hline $0-1$ line & $9(31 \cdot 1 \%)$ & $10(47 \cdot 6 \%)$ & $10(33.3 \%)$ & $8(36.5 \%)$ & $37(36 \cdot 3 \%)$ \\
\hline 2 lines & $11(37 \cdot 9 \%)$ & $9(42.9 \%)$ & $3(10 \cdot 0 \%)$ & $3(13 \cdot 6 \%)$ & $26(25 \cdot 5 \%)$ \\
\hline 3 lines & $7(24 \cdot 1 \%)$ & $2(9 \cdot 5 \%)$ & $5(16 \cdot 7 \%)$ & $10(45 \cdot 4 \%)$ & $24(23 \cdot 5 \%)$ \\
\hline 4 lines & $2(6.9 \%)$ & $0(0.0 \%)$ & $4(13 \cdot 3 \%)$ & $1(4 \cdot 5 \%)$ & $7(6.9 \%)$ \\
\hline 5 lines & - & - & $8(26 \cdot 7 \%)$ & $0(0 \cdot 0 \%)$ & $8(7 \cdot 8 \%)$ \\
\hline Total number of cases & $29(100 \cdot 0 \%)$ & $21(100 \cdot 0 \%)$ & $30(100 \cdot 0 \%)$ & $22(100 \cdot 0 \%)$ & $102(100 \cdot 0 \%)$ \\
\hline
\end{tabular}

Table 3 Average visual improvement in lines on Snellen chart in different subgroups of patients

\begin{tabular}{|c|c|c|c|c|}
\hline \multirow{3}{*}{$\begin{array}{l}\text { Corrected } \\
\text { initial } \\
\text { visual } \\
\text { acuity }\end{array}$} & \multicolumn{4}{|c|}{ Average visual improvement in lines } \\
\hline & \multicolumn{2}{|c|}{ Age in years } & \multicolumn{2}{|c|}{ Anisometropia in dioptres } \\
\hline & 6 to 12 & 13 to 20 & 4Dorless & More than $4 D$ \\
\hline $6 / 24$ & $1 \cdot 7$ & $1 \cdot 2$ & $1 \cdot 8$ & $1 \cdot 1$ \\
\hline $6 / 36$ & $2 \cdot 7$ & $1 \cdot 8$ & $2 \cdot 6$ & $1 \cdot 8$ \\
\hline
\end{tabular}

lines of improvement related to the degree of anisometropia. Table 3 shows the average visual improvement in lines on the Snellen chart according to age and degree of anisometropia. The general impression given by Tables 1 and 3 is that the prognosis for younger patients (6 to 12 years) is better than for older ones (13 to 20 years). Similarly, Tables 2 and 3 suggest that the prognosis is better in patients having anisometropia of 4 dioptres or less. However, statistical tests of significance did not confirm this. For Table 1, so far as the group of patients with corrected initial visual acuity $6 / 24$ or better is concerned, Wilcoxon's rank sum test ${ }^{78}$ gives $p>0 \cdot 20$. Thus the apparent difference in the prognosis of the 2 age groups does not attain statistical significance. And for the group with corrected initial visual acuity $6 / 36$ or worse this test gives $p>0 \cdot 10$, again not significant. Wilcoxon's rank sum test applied to Table 2 relating to subjects with corrected initial visual acuity $6 / 24$ or better shows that the prognosis of patients with anisometropia of 4 dioptres or less is significantly better than those with anisometropia greater than 4 dioptres $(\mathrm{p}<0 \cdot 01)$. For patients with corrected initial visual acuity $6 / 36$ or worse the differences in prognosis fail to attain statistical significance $(0 \cdot 10<p<0 \cdot 20)$. One can therefore conclude that patients with corrected initial visual acuity $6 / 24$ or better fare better in both the age groups if the extent of anisometropia is 4 dioptres or less. No such categorical statement can be made in either age group if their corrected initial visual acuity is $6 / 36$ or worse.

Stereopsis as tested with the Titmus fly and circles was present in $41(40 \cdot 2 \%)$ patients of all ages before treatment. In 30 of them it improved further with treatment, and stereoacuity as high as $\mathbf{4 0}$ seconds of arc was attained in 18 of them. Of the 61 (59.9\%) who gave negative response on the Titmus test before treatment 20 achieved it with treatment; the range of stereoacuity in them varied between 200 and 600 seconds of arc. Sixty-two patients $(60 \cdot 8 \%)$ showed fusion on the Worth 4-dot test before treatment. Of the $40(39 \cdot 2 \%)$ patients who gave a negative response on this test before treatment 12 showed the presence of fusion on this test after treatment. Table 4 charts the state of binocular vision before and after treatment separately for the 2 age groups.

\section{Discussion}

The results of treatment in a large series of patients with strabismus amblyopia have been reported, but reported data on anisometropic amblyopia without strabismus are scarce. The subject has also received little attention in textbooks. This is probably because

Table 4 State of binocular vision in the 2 age groups before and after amblyopia treatment

\begin{tabular}{|c|c|c|c|c|c|}
\hline \multirow[t]{2}{*}{ Age in years } & \multirow{2}{*}{$\begin{array}{l}\text { Total number } \\
\text { of patients }\end{array}$} & \multicolumn{2}{|c|}{ Stereopsis present on Titmus test } & \multicolumn{2}{|c|}{ Fusion present on Worth 4-dot test } \\
\hline & & Before therapy & After therapy & Before therapy & After therapy \\
\hline $\begin{array}{l}6 \text { to } 12 \\
13 \text { to } 20\end{array}$ & $\begin{array}{l}56(100 \cdot 0 \%) \\
46(100 \cdot 0 \%)\end{array}$ & $\begin{array}{l}23(41 \cdot 1 \%) \\
18(39 \cdot 1 \%)\end{array}$ & $\begin{array}{l}35(62 \cdot 5 \%) \\
26(56 \cdot 5 \%)\end{array}$ & $\begin{array}{l}35(62 \cdot 5 \%) \\
27(58 \cdot 7 \%)\end{array}$ & $\begin{array}{l}42(75 \cdot 0 \%) \\
32(69 \cdot 6 \%)\end{array}$ \\
\hline Total & $102(100 \cdot 0 \%)$ & $41(40 \cdot 2 \%)$ & $61(59 \cdot 8 \%)$ & $62(60 \cdot 8 \%)$ & $74(72 \cdot 6 \%)$ \\
\hline
\end{tabular}


cases of anisometropic amblyopia without strabismus are detected late, and so little or no effort is usually made to treat them. The prognosis is thought to be poor, since it has been established that reversal of amblyopia after the age of 6 years in strabismic patients is uncommon.

McMullen $^{4}$ advised patching for patients of anisometropic amblyopia under the age of 10 years. Bishop ${ }^{5}$ found the treatment of patients over the age of 11 years to give poor results. Phillips found that treatment of anisometropic amblyopia by patching at least until the age of 13 years is possible. ${ }^{9}$ Sullivan $^{10}$ treated patients up to the age of 12 years and observed that improvement in visual acuity seemed to decrease with age. Our study shows that, although children of 6 to 12 years improved in their vision more often than the older persons did, improvement was nevertheless observed in a considerable number $(50.0 \%)$ of patients in the 13 to 20 years age group. This is contrary to earlier observations that in anisometropic amblyopia the prognosis is poor in patients over the age of 12 . In this context it is worth recalling that some of our patients above 15 years of age showed much more improvement than did some of our young patients below 10 years of age. It is therefore worth treating patients with anisometropic amblyopia even after the age of 15 years.

Children with a visual acuity of $6 / 60$ or worse were a problem group. Patching of the normal eye in them at the beginning was intolerable. Therefore patching of the amblyopic eye and pleoptic therapy were instituted as initial therapy. Out of 27 such patients the visual acuity improved in 16 . This shows that inverse occlusion and pleoptic therapy have a definite place in the treatment of dense anisometropic amblyopia.

Since the great majority of the patients with anisometropic amblyopia had some form of binocular vision, the incidence of subsequent deterioration of vision in the amblyopic eye after treatment is likely to be low. However, it is desirable to monitor these patients closely for signs of regression. Though in such an eventuality patching of the nonamblyopic eye rapidly re-establishes the previously gained good visual acuity, we did not want to take any chance, and therefore advised our patients to continue occlusion of the better eye once a week for about 3 hours. This could easily be done at home on Sundays without curtailing social or outdoor activities.

I thank Mr G. P. Mathur, statistician, New Delhi Tuberculosis Centre, New Delhi, for statistical analysis of the data. I also thank Mr Baljit Singh and Mrs Neelam Upamanyu, orthoptists in the department, for technical assistance.

\section{References}

1 Cibis LM. Treatment of amblyopia. In: Becker B, Burde RM, eds. Current Concepts in Ophthalmology. St Louis: Mosby, 1969: 2: 222.

2 Duke-Elder S, Wybar K. Ocular motility and strabismus. In: Duke-Elder S, ed. System of Ophthalmology. London: Kimpton, 1973: 6: 296.

3 Hurtt J, Rasicovici A, Windsor CE. Comprehensive Review of Orthoptics and Ocular Motility, Theory, Therapy, and Surgery. 2nd ed. St Louis: Mosby, 1977: 166.

4 McMullen WH. Some points on anisometropia. Trans Ophthalmol Soc UK 1939; 59: 119-24.

5 Bishop JW. Treatment of amblyopia secondary to anisometropia. Br Orthopt J 1957; 14: 68.

6 Duke-Elder S, Wybar K. Ocular motility and strabismus. In: Duke-Elder S, ed. System of Ophthalmology. London: Kimpton, 1973; 6: 439-41.

7 Wilcoxon F. Individual comparisons by ranking methods. Biometrics Bull 1945; 1: 80-3.

8 Armitage P. Statistical Methods in Medical Research. Oxford: Blackwell, 1971: 396.

9 Phillips CI. Strabismus, anisometropia, and amblyopia. Br J Ophthalmol 1959; 43: 449-60.

10 Sullivan M. Results in the treatment of anisometropic amblyopia. Am Orthopt J 1976; 26: 37-9. 